\title{
Development of decontamination and detergents for the nuclear industry
}

\begin{abstract}
At the enterprises of the radiochemical industry in the world, the task is to clean the technological and research equipment, overalls, and personnel from contamination with radioactive products. This task is especially relevant in case of emergencies, for example, such as an accident at a nuclear power plant in Fukushima, Japan. A review of the deactivation methods currently used is reviewed. It has been shown that the most typical pollutants are mixtures of radionuclides ${ }^{137} \mathrm{Cs},{ }^{144} \mathrm{Ce},{ }^{144} \mathrm{Pr}$, ${ }^{90} \mathrm{Sr}$, and ${ }^{239} \mathrm{Pu}$. All these elements are prone to the formation of chelate complexes. Therefore, complexing substances should be an essential component of deactivation solutions that form stable, water-soluble complex compounds with these radionuclides. When creating the recipe, we chose those complexing agents with the most persistent complex compounds with the expected pollutants. For research and testing in real conditions, we have prepared three types of technical detergents of various compositions with the code name MDS for decontaminating various surfaces, equipment, and workwear. The composition of these preparations consists mainly of an optimized mixture of surfactants, complexing agents, corrosion inhibitors, and processing aids. The studies were conducted to evaluate the possibility of using these funds for deactivation of premises, equipment, washing clothes in the Federal Unitary Enterprise "Mayak" and at its branch NIKIET in town Zarechny at Beloyarskyaya Nuclear Power Station in Russia. The effectiveness of deactivation was judged by the amount of residual contamination of the surface of the samples. The deactivating ability of MDS preparations for stainless, carbon steel, and plastic contaminated with $\beta$ - and $\alpha$-emitting nuclides was tested. The possibility of using MDS detergents for the deactivation of platinum ampoules stored as radioactive waste was assessed. The possibility of using MDS detergents for the deactivation of fabric materials, including underwear and work clothes, was also evaluated. The tests showed the high efficiency of the developed detergent MDS compared to the existing and currently used deactivation agents.
\end{abstract}

Keywords: deactivation, decontamination, detergents, chelating complexing agents, radiation pollution, radiation contamination removal, ${ }^{137} \mathrm{Cs},{ }^{144} \mathrm{Ce},{ }^{144} \mathrm{Pr},{ }^{90} \mathrm{Sr},{ }^{239} \mathrm{Pu}$
Volume 5 Issue 4 - 202 I

\section{Kudryavtsev $\mathrm{P}$}

Professor, Deputy Director for Research and Development, KUD Industries - Israeli Technology Research Center, Israel

\section{Correspondence: Kudryavtsev P, Professor, Deputy Director for Research and Development, KUD Industries - Israeli} Technology Research Center, Israel, Email pgkudr89@gmail.com

Received: July 15, 202I | Published: August 06, 2021

\section{Introduction}

The development of nuclear energy for peaceful purposes requires a particularly careful attitude to the radiation safety of the personnel working at nuclear power plants and factories that provide nuclear fuel cycles and nuclear research laboratories and medical institutions. Experience in analysis of accidents that happen at nuclear facilities in various countries over the past few years also emphasizes the importance of creating materials for the deactivation of the affected areas. A critical goal of radiation safety is to create a new and effective means for deactivating radiation-contaminated surfaces. Figure 1 shows the classification of existing deactivation methods.

Deactivation is essentially the process of desorption of radionuclides and radioactive particles or the removal of oxide films and deposits from the surface of a material. The patterns of deactivation are closely related to the nature of the sorption of radioactive contaminants, the quality of the sorption surface and the properties of the formed oxides. In the case of physical sorption, the forces that bind the sorbed particle to the surface are weak (binding energy 4-40 $\mathrm{kJ} / \mathrm{mol}$ ); therefore, desorption is easy: it is enough to increase the temperature of the medium in contact with the surface. Thus, the activation energy of the desorption process usually does not exceed $20 \mathrm{~kJ} / \mathrm{mol}$. In real systems, various types of pollution are generally present. As the time of contact of the radioactive substance with the surface increases, the proportion of poorly fixed contaminants decreases and the balance of chemically sorbed forms increases. This increases the bond strength of the sorbed components with the surface. Thus, the rate of desorption is proportional to the acidity of the stripping solution used for deactivation. The introduction of surfactants and complexing agents into the solution promotes desorption since it increases the chemical potentials of all sorbed ions and binds the cations passing into the solution into stable complexes. ${ }^{1}$

At present, there exists a full spectrum of means for deactivation of surfaces contaminated with radionuclides. Currently known is a wide range of means for deactivation of surfaces contaminated with radionuclides. Some of them are used for cleaning metal surfaces of equipment and tools, the second for washing floors and walls in industrial and residential areas, and others for washing the personnel, and separately for laundering fabric materials, including linens and clothing contaminated with radioactive and toxic metals. A disadvantage of these compositions is a significant reduction in fabric strength due to the application of highly aggressive agents, corrosion of the equipment, and, most importantly, large consumption of energy and water and, as a consequence, vast amounts of low-active wastewater to be further purified. The most common contaminants are mixtures of ${ }^{137} \mathrm{Cs},{ }^{144} \mathrm{Ce},{ }^{144} \mathrm{Pr},{ }^{90} \mathrm{Sr}$, and ${ }^{239} \mathrm{Pu}$. All these elements tend to form chelate complexes. On the one hand, this leads to the fact that they are firmly held on the contaminated surfaces; on the other hand, this fact makes it possible to create chelate complexes, which will securely hold these elements in a solution, preventing them 
from depositing on surfaces. An essential component of deactivation solutions should be complexing substances, which form stable watersoluble complexes with these radionuclides. Compounds used for such deactivation are mainly polyphosphates, polycarboxylic amino acids, citric acid, oxalic acid, tartaric acid, hydrofluoric acid and salts thereof - citrates, oxalates, tartrates and fluorides. The most often used polyphosphate is sodium hexametaphosphate that forms soluble complexes with many cations ( $\mathrm{Sr}, \mathrm{Ca}, \mathrm{Ba}, \mathrm{Ce}, \mathrm{Zr}$, etc.). Furthermore, it softens water, thus enhancing the effectiveness of deactivation solutions containing fatty soaps.

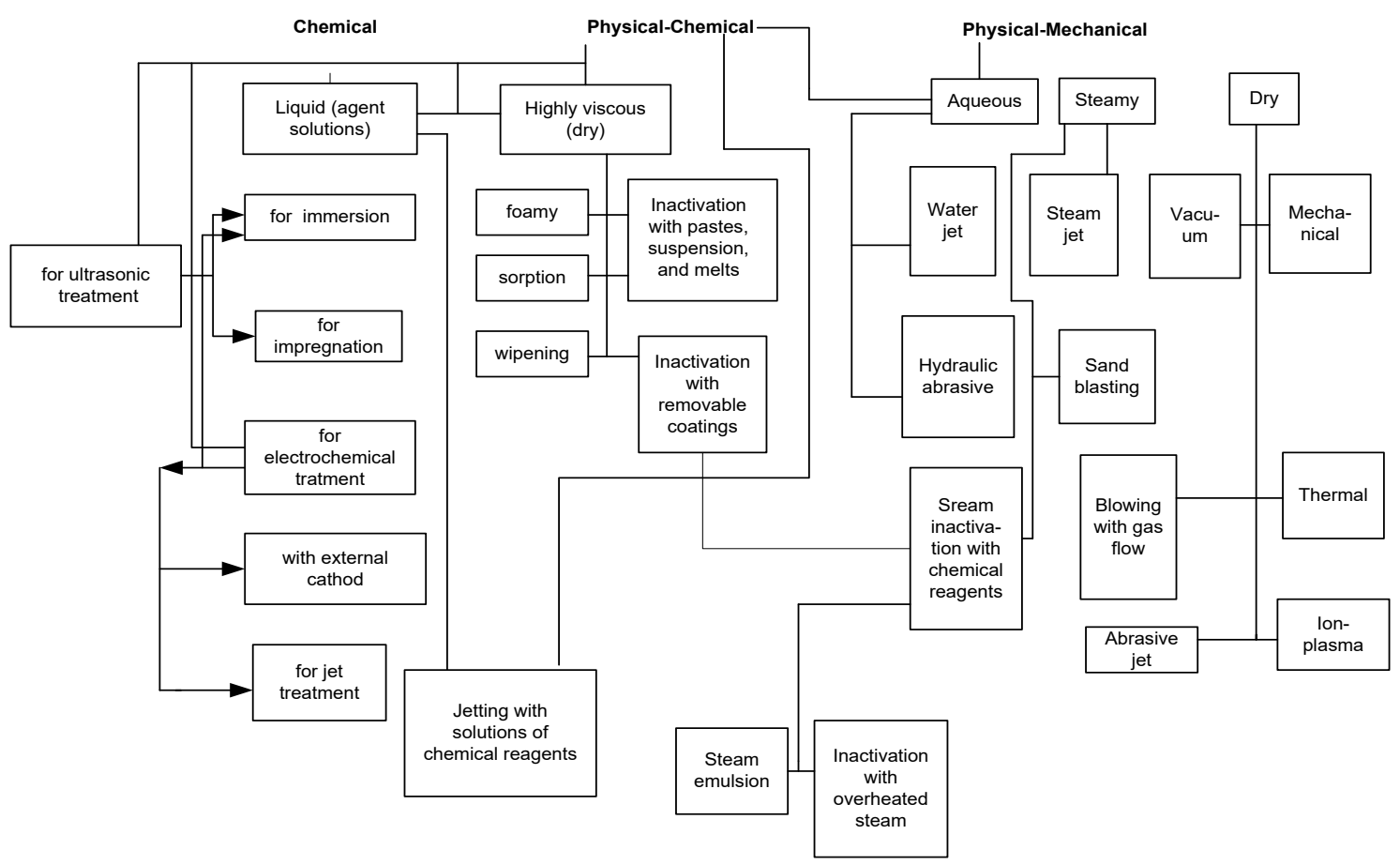

Figure I Classification of deactivation methods.

Among organic complexing agents such as polycarboxylic amino acids usually known as chelating agents, the most significant importance for the deactivation has ethylene diamine tetraacetic acid (EDTA) and its disodium salt. The structure of complex ions formed by EDTA is shown in Figure 2. Chelate compounds are intra-complex or cyclic complex compounds characterized by a claw-like structure. They are formed by the interaction of metal ions with polydentate ligands, which have several donor centers. Chelate complex compounds contain a central ion-complexing agent and ligands coordinated around it. The inner sphere of the chelate consists of cyclic groups, including a complexing agent. In coordination chemistry, EDTA is a member of the amino polycarboxylic acid ligand family. EDTA usually binds to a metal cation through its two amines and four carboxylates. Many of the resulting coordination compounds adopt octahedral geometry. These octahedral complexes are chiral. Many EDTA complexes can take on more complex structures due to the formation of an additional bond with water molecules, that is, with the appearance of a complexing agent with a coordination number of 7 or higher. It is also possible to replace one carboxylate arm with water molecules. The presence of closed cycles in the structure of complexions leads to a significant increase in their strength.

The strength of the complexes formed by complexones of the EDTA type is significantly higher than the strength of complexes of citric and oxalic acids. For example, the strength of the oxalate complexes of bivalent Fe by 15 orders less than the corresponding strength of the EDTA complexes. High-strength complexes formed by the chelating agents result from specificities of their structure. It is known that the strength of a complex compound is largely determined by the presence of structural rings in the intra-complex compound, the number of members in the ring structure, and the number of such rings. The most durable is a five-membered ring; its strength is higher when it contains a nitrogen atom. The more is the number of five-membered rings in the complex, and the higher is its durability. An EDTA molecule contains two aminodiacetate groups linked by an ethylene bridge. Such a structure allows the EDTA molecule to form many cycles with metal, including five-membered cycles which are the most stable. Six-membered rings are slightly lower in their stability, while the stability of four- and seven-membered cycles is lower to a much greater extent. The presence of four carboxyl groups in the molecules of EDTA and its salts allows the formation of chelate compounds with strong cations of two-, three-, and tetravalent metals. The strength of the complexes formed by EDTA, to a large extent, depends on the $\mathrm{pH}$ of the medium, and this dependence is not the same for different cations. Most tetravalent metal cations form complexes in strongly acidic solutions $(\mathrm{pH}=1)$, and trivalent - at $\mathrm{pH} 2 \div 3$. The maximum stability of the complexes of heavy divalent cations is observed at $\mathrm{pH}=3 \div 5$. EDTA complexes with alkaline earth metals dissociate at $\mathrm{pH} 6 \div 7$.

In the course of studies conducted during the development of deactivation detergents, the author designed the formulation of deactivation detergent agents based on conventional detergent additives with a complex of chelating agents capable of binding radionuclides into stable chelate complexes. Based on the proposed agents, the formulation can be prepared in the form of powders, liquid concentrates, shampoos, soaps, and gels. An example of such an invention is a paste for cleaning hands from dirt. It allows you to 
quickly and without additional means to remove household impurities from the skin, waste fatty oils, and greases, as well as radioactive contaminants, while not irritating the skin. In this regard, the paste for dry hand cleaning contains wt. \%: polyvinyl alcohol $9 \div 12 \%$; glycerol $2 \div 4 \%$; dicarboxybetaine $1.2 \div 2.4 \%$; sodium chloride $0.3 \div 0.6 \%$; benzoic or salicylic acid $0.1 \div 0.2 \%$; the rest is water. It may also optionally contain citric acid and aluminum nitrate in an amount of $1 \div 2$ wt. $\%$ and $0.010 \div 0.015$ wt. $\%$ respectively. ${ }^{5}$ However, this invention has an exclusively narrow purpose. Close to our proposed method are inventions of a means for removing contaminants from radioactive and toxic metals ${ }^{6,8}$ and a way for decontaminating the surface of equipment and rooms of nuclear plants. ${ }^{7}$ The essence of these inventions is the manufacture of a powdered detergent, the solution of which serves to remove contaminants of radioactive and toxic metals from various surfaces. It consists of polyaminocarboxylic acids or their salts, surfactants, inorganic polyphosphates and other components of synthetic detergents. In this case, the product contains $3 \div 10$ wt. $\%$ polyaminocarboxylate or its alkaline salts and an additional $1 \div 5$ wt. $\%$ polyaminophosphate. These inventions can underlie the creation of stronger detergent compositions containing highly effective chelating agents.

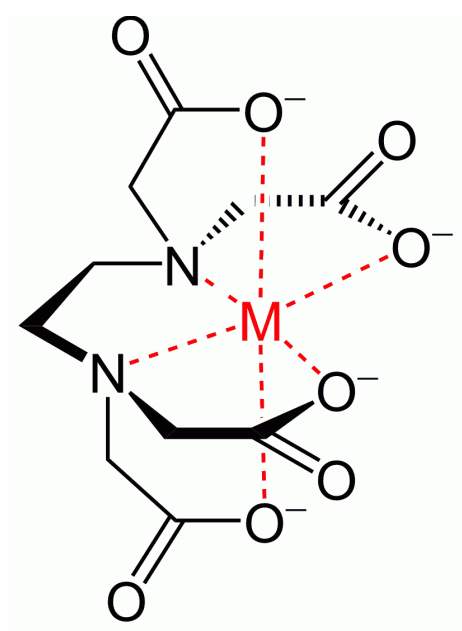

Figure 2 The most typical form of a chelate complex ion formed by ethylenediaminetetraacetic acid and a transition metal ion.

In the deactivation of polymeric materials, complexones are used so far to a limited extent due to their relatively high cost. Widely used is only an oxalic acid. This is because of its availability and ability to work in solutions as an acid and as a complexing agent. Oxalic acid forms stable complexes with most common radionuclides $(\mathrm{Zr}, \mathrm{Nb}$, $\mathrm{Fe}, \mathrm{Co}, \mathrm{Pu}, \mathrm{Ru}, \mathrm{Rh}$, etc.). Many ordinary metal oxalates moderately or poorly soluble in water. The least soluble oxalates are oxalates of Th and rare earth elements. However, all oxalate compounds can be dissolved in mineral acids, and most of them - more than the oxalate ions due to the formation of complexes. When creating the recipe, several different complexing agents produced industrially were tested. Complexing agents were selected so that they had the most durable complexes compounds with the alleged pollutants.

\section{The method of manufacture and test methods of technical detergent}

The following three types of technical washing means of different compositions (i.e., MDS-1, MDS-2, 3-MDS) were prepared for research and testing in real conditions. The compositions of these preparations include, in general, an optimized mixture of surfactants, complexing agents, corrosion inhibitors, and processing aids (Table 1). The presented preparations differ from each other in the content of the reagents used. Studies were conducted to assess the possibility of using these substances for the deactivation of rooms, equipment, and washing clothes (work uniform) at Federal Unitary Enterprise "Mayak" and its branch NIKIET in town Zarechny at Beloyarskyaya Nuclear Power Station. By manufacturer's recommendations, the concentration of the solutions should be in the range of $5 \%$ to $10 \%$. A working-level chosen for determining the deactivation capacity of the tested compounds was chosen equal to $5 \%$. The author investigated the performance of TMS individually and in combinations with MDS-1: MDS-2: MDS-3 in a 1: 1: 1 ratio. This combination was conventionally designated "MDS-4."

Table I The approximate composition of MDS-type technical washing means

\begin{tabular}{ll}
\hline Name of the component & Content, \% \\
\hline Sulfanol & Oct-20 \\
Sodium tripolyphosphate & $50-60$ \\
Chelate-forming additives & $05-$ Oct \\
Sodium sulfate & $20-30$ \\
Technological additives & $05-$ Oct \\
\hline
\end{tabular}

Deactivation was carried out in two ways: by dipping in a solution with 1-hour cycles and by rubbing the surface with a cloth moistened with the prepared solution. The treatment was carried out with 3-minute periods. The treated samples were made of stainless steel and carbon steel. Samples were contaminated with droplets of a solution prepared from technological samples of Plant 235 at the Mayak Production Association, that contained $\alpha$ - (basic radionuclide ${ }^{239} \mathrm{Pu}$ ) and $\beta$ - (basic radionuclide ${ }^{90} \mathrm{Sr}$ ) emitting nuclides. In this case, baseline levels of radioactive contamination were as follows: no more than $2,000 \alpha-\left(\mathrm{cm}^{2} \bullet \mathrm{min}\right)^{-1}$ and $3000 \beta-\left(\mathrm{cm}^{2} \bullet \mathrm{min}\right)^{-1}$. The efficiency of deactivation was evaluated in terms of residual contamination on the surfaces of the samples. Measurements of the initial and the residual contamination of the samples were performed on a twochannel counting rate meter UIM2-2D and detection units BDZA100 , and BDZB-100L. The contamination of samples was calculated as the arithmetic average of three to five parallel measurements. The main criterion for the effectiveness of deactivation was a deactivation factor determined as a ratio of the levels of radioactive contamination on samples before and after deactivation. The coefficient of in deactivation activation $\mathrm{K}_{\mathrm{d}}$ was calculated according to the following formula:

$$
K_{\ddot{a}}=\frac{A_{o}}{A_{i \tilde{n} \tilde{o}}}
$$

where: $\mathrm{A}_{\mathrm{o}}$ is initial contamination of the sample $\left(\mathrm{cm}^{2} \cdot \mathrm{min}\right)^{-1}$;

$\mathrm{A}_{\text {ост }}$ is residual contamination of the sample after the deactivation $\left(\mathrm{cm}^{2} \cdot \min \right)^{-1}$.

\section{Deactivation of structural materials}

There are various methods for surface deactivation of structural materials such as carbon and stainless steel. One such example is an invention designed to increase the effectiveness of deactivation, reduce the volume of generated solid and liquid radioactive waste. It uses an etching composition based on oxyethylcellulose (OEC) containing $8 \div 14 \%$ OEC, $15 \div 18 \%$ hydrofluoric acid, $24 \div 33 \%$ nitric acid and water. This composition is kept on a decontaminated surface for 10 
to 18 hours, after which the cured composition and the products of its interaction with the oxide film on steel are removed. ${ }^{4}$ This method is quite time-consuming and really applicable only for cleaning surfaces of metals resistant to aggressive acids. Results of the deactivation of structural materials from contamination with $\beta$-radionuclides by the immersion method at a temperature of $60^{\circ} \mathrm{C}$ are shown in tables Table 2 and Table 3. As seen from Table 2, the MDS-type technical washing means agents quite effectively remove $\beta$-radionuclides from the surface of the stainless steel. Deactivation of carbon steel samples with MDS-2 MDS-3, and "MDS-4" is unsatisfactory. MDS1 has enough capacity for the deactivation of contaminants on the surfaces of structural materials of both types. The author also tested the deactivation ability of MDS agents concerning the $\alpha$-emitting nuclides. The results are shown in the tables Table 4 and Table 5.

Table 2 Evaluation results of inactivating capacity of MDS-type technical washing means agents by immersion method; the tests were conducted on stainless samples contaminated with $\beta$-emitting nuclides

\begin{tabular}{llll}
\hline $\begin{array}{l}\text { Technical washing } \\
\text { means }\end{array}$ & $\begin{array}{l}\text { Initial surface } \\
\text { contamination } \\
\left(\mathbf{c m}^{2} \bullet \mathbf{m i n}\right)^{-1}\end{array}$ & $\begin{array}{l}\text { Residual surface } \\
\text { contamination } \\
\left(\mathbf{c m}^{2} \bullet \mathbf{m i n}\right)^{-1}\end{array}$ & $\begin{array}{l}\text { The total } \\
\text { deactivation factor } \\
\text { of three cycles }\end{array}$ \\
\hline MDS-I $\left(\mathrm{t}=60^{\circ} \mathrm{C}\right)$ & 2450 & Background & $>120$ \\
MDS- $\mid\left(\mathrm{t}=20^{\circ} \mathrm{C}\right)$ & 2790 & 23 & 143 \\
MDS-2 & 2847 & Background & $>140$ \\
MDS-3 & 2125 & 32 & $>66$ \\
«MDS-4» & 1200 & Background & $>60$ \\
\hline
\end{tabular}

Table 3 Evaluation results of inactivating capacity of MDS-type technical washing means agents by immersion method; the tests were conducted on carbon-steel samples contaminated with $\beta$-emitting nuclides

\begin{tabular}{llll}
\hline $\begin{array}{l}\text { Technical washing } \\
\text { means }\end{array}$ & $\begin{array}{l}\text { Initial surface } \\
\text { contamination } \\
\left(\mathbf{c m}^{2} \bullet \mathbf{m i n}\right)^{-1}\end{array}$ & $\begin{array}{l}\text { Residual surface } \\
\text { contamination } \\
\left(\mathbf{c m}^{2} \bullet \mathbf{m i n}^{-1}\right.\end{array}$ & $\begin{array}{l}\text { The total deactivation } \\
\text { factor of three cycles }\end{array}$ \\
\hline MDS-I $\left(\mathrm{t}=60^{\circ} \mathrm{C}\right)$ & 2679 & Background & $>180$ \\
MDS-I $\left(\mathrm{t}=20^{\circ} \mathrm{C}\right)$ & 1250 & 85 & 14,7 \\
MDS-2 & 2400 & 370 & 6,5 \\
MDS-3 & 3197 & 1002 & 3,2 \\
«MDS-4» & 2510 & 1040 & 2,4 \\
\hline
\end{tabular}

Table 4 Valuation results of inactivating capacity of MDS-type technical washing means agents by immersion method; the tests were conducted on stainless steel samples contaminated with $\alpha$-emitting nuclides

\begin{tabular}{llll}
\hline Technical washing means & $\begin{array}{l}\text { Initial surface } \\
\text { contamination } \\
\left(\mathbf{c m}^{2} \bullet \text { min }\right)^{-1}\end{array}$ & $\begin{array}{l}\text { Residual surface } \\
\text { contamination }\end{array}$ & $\begin{array}{l}\text { The total deactivation } \\
\text { factor of three cycles }\end{array}$ \\
\hline MDS-I $(\mathrm{t}=60 \mathrm{oC})$ & 650 & 3,3 & 197 \\
MDS-I $\left(I=20^{\circ} \mathrm{C}\right)$ & 1820 & 117 & 15,6 \\
MDS-2 & 1595 & 13,5 & 118 \\
MDS-3 & 1490 & 246 & 6,1 \\
«MDS-4» & 2067 & 490 & 4,2 \\
\hline
\end{tabular}

Table 5 Evaluation results of inactivating capacity of MDS-type technical washing means agents by immersion method; the tests were conducted on carbon steel samples contaminated with $\alpha$-emitting nuclides

\begin{tabular}{llll}
\hline Technical washing means & $\begin{array}{l}\text { Initial surface } \\
\text { contamination } \\
\left(\mathbf{c m}^{2} \bullet \mathbf{m i n}\right)^{-1}\end{array}$ & $\begin{array}{l}\text { Residual surface } \\
\text { contamination } \\
\left(\mathbf{c m}^{2} \bullet \mathbf{m i n}\right)^{-1}\end{array}$ & $\begin{array}{l}\text { The total deactivation } \\
\text { factor of three cycles }\end{array}$ \\
\hline MDS-I $\left(\mathrm{t}=60^{\circ} \mathrm{C}\right)$ & 1513 & 8,3 & 182 \\
MDS-I $\left(\mathrm{t}=20^{\circ} \mathrm{C}\right)$ & 1206 & 415 & 2,9 \\
MDS-2 & 2380 & 2254 & 1,05 \\
MDS-3 & 2254 & 2251 & 1,05 \\
«MDS-4» & 1915 & 1810 & 1,05 \\
\hline
\end{tabular}


As seen from the tables Table 4, Table 5, the MDS-1 type of technical washing means effectively inactivates both stainless and carbon steel from $\alpha$-radionuclide. Apparently, in this case, the high efficiency is provided due to the significant corrosive action of this agent on steel products. To test this assumption, the author estimated the corrosion rate of carbon steel and stainless steel in a 5\% solution of MDS- 1 at $60^{\circ} \mathrm{C}$. Corrosion rates for stainless steel did not exceed $0.4 \mathrm{~g} /\left(\mathrm{m}^{2} \bullet \mathrm{h}\right)$, and for carbon steel, the corrosion rate was $5.3 \mathrm{~g} /\left(\mathrm{m}^{2} \bullet \mathrm{h}\right)$ on average. The results of further tests showed (Table 4) that MDS-2 is useful for treating objects made only from stainless steel. Of all the agents mentioned above, the highest deactivation ability was shown by MDS-1. Therefore, this agent was further tested by immersion deactivation at room temperature. The results are shown in Tables 2 to 5 . With a decrease in the heat of the deactivation process, the effectiveness of the drug MDS-1 decreases slightly. In the next stage of the research, the author evaluated the ability of deactivation by rubbing the solution into the contaminated surface. The rubbing tests were conducted only at room temperature since the 3-minute cycle did not allow to maintain the solution at high temperature over a longer cycle. Results of the deactivation of structural materials by the rubbing method are shown in Table 6 and Table 7. As can be seen from Table 6 and Table 7, at the rubbing method, high coefficients of deactivation efficiency were obtained in treating stainless steel samples contaminated with $\beta$-emitting nuclides. In general, for samples of all types, deactivation by the immersion method appeared to be more efficient because in this case, the deactivation treatment was conducted at an elevated temperature and with a long time of contact between the sample surface and the deactivation solution.For example, in the immersion method, the deactivation factors obtained in cleaning $\alpha$-contaminated carbon steel samples were two orders higher than in the case of deactivation of the same samples by the rubbing method.

Table 6 Evaluation results of the deactivation capacity of MDS-type technical washing mean agents by rubbing method at $20^{\circ} \mathrm{C}$. The tests were conducted on stainless steel samples

\begin{tabular}{lllll}
\hline $\begin{array}{l}\text { Technical } \\
\text { washing means }\end{array}$ & $\begin{array}{l}\text { Type of } \\
\text { contamination }\end{array}$ & $\begin{array}{l}\text { Initial surface } \\
\text { contamination }\left(\mathbf{c m}^{2} \bullet \mathbf{m i n}\right)^{-1}\end{array}$ & $\begin{array}{l}\text { Residual surface } \\
\text { contamination }\left(\mathbf{c m}^{2} \mathbf{m}_{\mathbf{m i n}}\right)^{-1}\end{array}$ & $\begin{array}{l}\text { The total deactivation } \\
\text { factor of three } \mathbf{c y c l e s}\end{array}$ \\
\hline MDS-1 & $\alpha$ & 2340 & 285 & 8 \\
& $\beta$ & 2615 & Background & $>130$ \\
MDS-2 & $\alpha$ & 1615 & 81 & 20 \\
& $\beta$ & 2600 & 47 & 55 \\
MDS-3 & $\alpha$ & 1570 & 36 & 44 \\
& $\beta$ & 1816 & Background & $>80$ \\
MDS-4 & $\alpha$ & 1685 & 164 & 10 \\
& $\beta$ & 2330 & Background & $>115$ \\
\hline
\end{tabular}

Table 7 Evaluation results of the inactivating capacity of MDS-type technical washing mean agents by rubbing method at $20^{\circ} \mathrm{C}$. The tests were conducted on carbon steel samples

\begin{tabular}{lllll}
\hline $\begin{array}{l}\text { Technical } \\
\text { washing means }\end{array}$ & $\begin{array}{l}\text { Type of } \\
\text { contamination }\end{array}$ & $\begin{array}{l}\text { Initial surface } \\
\text { contamination }\left(\mathbf{c m}^{2} \bullet \mathbf{m i n}\right)^{-1}\end{array}$ & $\begin{array}{l}\text { Residual surface } \\
\text { contamination }\left(\mathbf{c m}^{2} \bullet \mathbf{m i n}\right)^{-1}\end{array}$ & $\begin{array}{l}\text { The total deactivation } \\
\text { factor of three cycles }\end{array}$ \\
\hline MDS-I & $\alpha$ & 1956 & 1110 & 1,8 \\
& $\beta$ & 3287 & 1148 & 2,8 \\
MDS-2 & $\alpha$ & 1514 & 160 & 9,5 \\
& $\beta$ & 2216 & 636 & 3,5 \\
MDS-3 & $\alpha$ & 1066 & 356 & 2,9 \\
& $\beta$ & 2516 & 650 & 3,9 \\
MDS-4 & $\alpha$ & 1684 & 1180 & 1,4 \\
& $\alpha$ & 1978 & 1122 & 1,8 \\
\hline
\end{tabular}

\section{Deactivation of products from polymeric materials}

The desorption of ions from polymeric materials during their deactivation has several features. Polymeric materials retain sorbed radionuclides due to the presence in their composition of groups capable of ion-exchange: carboxyl, hydroxyl amino groups. The higher the content of such groups, the stronger the polymers retain radioactive contamination. On materials with chemically inert groups, radioactive substances are kept weaker. The bond strength of radioactive contamination with the surface also depends on the physicochemical form of the sorbed radionuclide. So, on some materials, simple ions are more firmly held, and on others - hydroxo complexes and colloids. Porosity and the tendency to swelling of some polymers lead to diffusion and penetration of radioactive substances into the interior of the material, which makes its deactivation very difficult. 
Depending on the difficulty of removing radionuclides from polymeric materials, they can be divided into four groups:

I. water efficiently removed (Cs);

II. desorbed by simple solutions of surfactants, acids, complexing agents ( $\mathrm{Sr}, \mathrm{Mn}, \mathrm{Co})$;

III. removed only with solutions containing combinations of deactivating agents (REE, Y, Fe, Am);

IV. hard to remove $(\mathrm{Zr}, \mathrm{Nb}, \mathrm{Ru}, \mathrm{Pu}, \mathrm{Po}, \mathrm{I}){ }^{3}$

As a rule, the removal of cationic contaminants improves with increasing acidity of the solution and in the presence of complexing agents. The effectiveness of surfactants in the deactivation of polymeric materials is explained not only by their washing action but also by the ability to form water-soluble relatively stable complexes with many radionuclides. ${ }^{3}$ The presence of extraneous cations in the solution improves the desorption of contaminants, and the use of isotopic exchange is also useful. The next stage of tests consisted of determination of the deactivation capacity of MDS-type agents on facing materials. The test specimens were made from plastics which are used mainly for coating floors of production facilities. Therefore, considering possible contamination conditions, the laboratory samples were contaminated by bringing them in contact with polyvinyl chloride plastic pre-contaminated with $\alpha$ - and $\beta$-radionuclides (by smear). The final washing of plastic samples was performed by rubbing the surface with the solution-containing cloth. The results are shown in Table 8 . As can be seen from Table 8 , all agents shown above are sufficiently active for inactivating plastics from both $\alpha$ - and $\beta$-emitting nuclides.

Table 8 Evaluation results of inactivating capacity of MDS-type technical washing means agents by rubbing method; the tests were conducted on plastic samples

\begin{tabular}{lllll}
\hline $\begin{array}{l}\text { Technical } \\
\text { washing means }\end{array}$ & $\begin{array}{l}\text { Type of } \\
\text { contamination }\end{array}$ & $\begin{array}{l}\text { Initial surface } \\
\text { contamination }\left(\mathbf{c m}^{2} \cdot \mathbf{m i n}\right)^{-1}\end{array}$ & $\begin{array}{l}\text { Residual surface } \\
\text { contamination }\left(\mathbf{c m}^{2} \bullet \mathbf{m i n}\right)^{-1}\end{array}$ & $\begin{array}{l}\text { The total deactivation } \\
\text { factor of three } \mathbf{c y c l e s}\end{array}$ \\
\hline MDS-1 & $\alpha$ & 1505 & 1,7 & 885 \\
& $\beta$ & 1590 & Background & $>80$ \\
MDS-2 & $\alpha$ & 1250 & 4,4 & 284 \\
& $\beta$ & 1225 & 7 & 175 \\
MDS-3 & $\alpha$ & 780 & 2,8 & 279 \\
& $\alpha$ & 1288 & Background & $>65$ \\
\hline
\end{tabular}

\section{Assessing the possibility of using MDS agents for deactivation platinum}

Currently, the Federal Unitary Enterprise "Mayak" is accumulating platinum elements from products returned for recycling. During operation, the elements were in contact with plutonium, as a result of which the $\alpha$-activity contamination reaches $150,000\left(\mathrm{~cm}^{2} \bullet \mathrm{min}^{-1}\right.$, the smear removed by the lie is $40,000\left(\mathrm{~cm}^{2} \cdot \mathrm{min}\right)^{-1}{ }^{9}$ To return the precious metal to industrial circulation, according to the standards,${ }^{10}$ platinum should be decontaminated to a total contamination value of not more than $1.0 \alpha$-particles $\left(\mathrm{cm}^{2} \cdot \mathrm{min}\right)^{-1}$, and the removed pollution should not be allowed, the dose rate of gamma-neutron radiation should not exceed $0.2 \mu \mathrm{Sv} / \mathrm{h}$. The purpose of these studies was to select and implement the most effective method of deactivating platinum products, ensuring minimal precious metal losses and returning platinum to production, and determining the actual damages of platinum during platinum waste disposal. During various series of experiments, it was found that the most effective method for the deactivation of platinum wastes is flux remelting $\left(\mathrm{CaO}+\mathrm{SiO}_{2}+\mathrm{A}_{2} \mathrm{O}_{3}\right)$ in an internal crucible from periclase and external corundum crucibles in an induction furnace at a temperature of $1770 \pm 10{ }^{\circ} \mathrm{C}$ for $60 \mathrm{~min}$. To reduce the level of contamination of platinum waste entering the smelter, as well as the content of impurities of various chemical elements, a technology was developed for preparing platinum waste for remelting, which includes the following steps:

I. Removal of nickel-copper coatings from the surface of platinum elements;

II. Removal of gas inlets and capillaries;

III. Fragmentation of elements into segments;
IV. Extraction of copper solders;

V. Liquid deactivation to levels of $50 \alpha$-particles $\left(\mathrm{cm}^{2} \bullet \mathrm{min}^{-1}\right.$

Based on the results of ${ }^{11}$ obtained in the course of the research, a technological scheme for platinum waste disposal was put into effect. The desorption of ions from metal surfaces during their deactivation is an activated exchange of ions entering surface compounds into solution ions. For all desorption curves, a rapid decrease in activity in the first minutes is typical, which is obviously due to the desorption of weakly fixed forms. Further, the desorption curves go to a straight section. For most cations, the desorption rate is proportional to the first or second degree of ion concentration $\mathrm{H}^{+}$. The order of the desorption reaction of $\boldsymbol{d}$ - and $\boldsymbol{f}$-element ions by $\mathrm{H}^{+}$ions depends on the anion forming the chelate complex and on the composition of the sorbed complex. The time of complete desorption of yttrium Y from platinum does not rely on the potential and ranges from 100 to $1000 \mathrm{~min}$. The metal potential affects the duration of desorption only if the valency of the ion changes during desorption. The activation energy for the desorption of chemically sorbed ions lies in the range $40-250 \mathrm{~kJ} / \mathrm{mol}$, for $\mathrm{Cs}^{+}$ion it is 54 , for yttrium $\mathrm{Y}^{3+}$ it is $67-75 \mathrm{~kJ} / \mathrm{mol} .^{1}$ In, ${ }^{1}$ a mechanism was proposed for the desorption of yttrium Y-type radionuclides from platinum:

$$
\begin{gathered}
{\left[\mathrm{Pt}(\mathrm{OH})-\mathrm{OYCl}_{2}\right]_{a d s}+\mathrm{H}_{\text {sol }}^{+} \leftrightarrow[\mathrm{Pt}(\mathrm{OH})-\mathrm{OH}]_{\text {ads }}+\mathrm{YCl}_{2 s o l}^{+}} \\
{\left[\mathrm{YCl}_{2}^{+}\right]_{a d s}+\mathrm{HSO}_{4 \text { sol }}^{-} \leftrightarrow \mathrm{YSO}_{4 \text { sol }}^{+}+2 \mathrm{Cl}_{\text {sol }}^{-}+H_{a d s}^{+}}
\end{gathered}
$$

The considered desorption model assumes that a single ionexchange mechanism sorbs ions. However, in real systems, the mechanism of fixation of radioactive contamination can be different. 
The studies were conducted to assess the possibility of using MDS agents in the step of the final cleaning of the ampoules (RTSCH $108,010)$ contaminated with ${ }^{239} \mathrm{Pu}$ before transmission of the ampoules to remelting. The type of platinum ampoules of RTSCH 108.010 is shown in Figure 3.

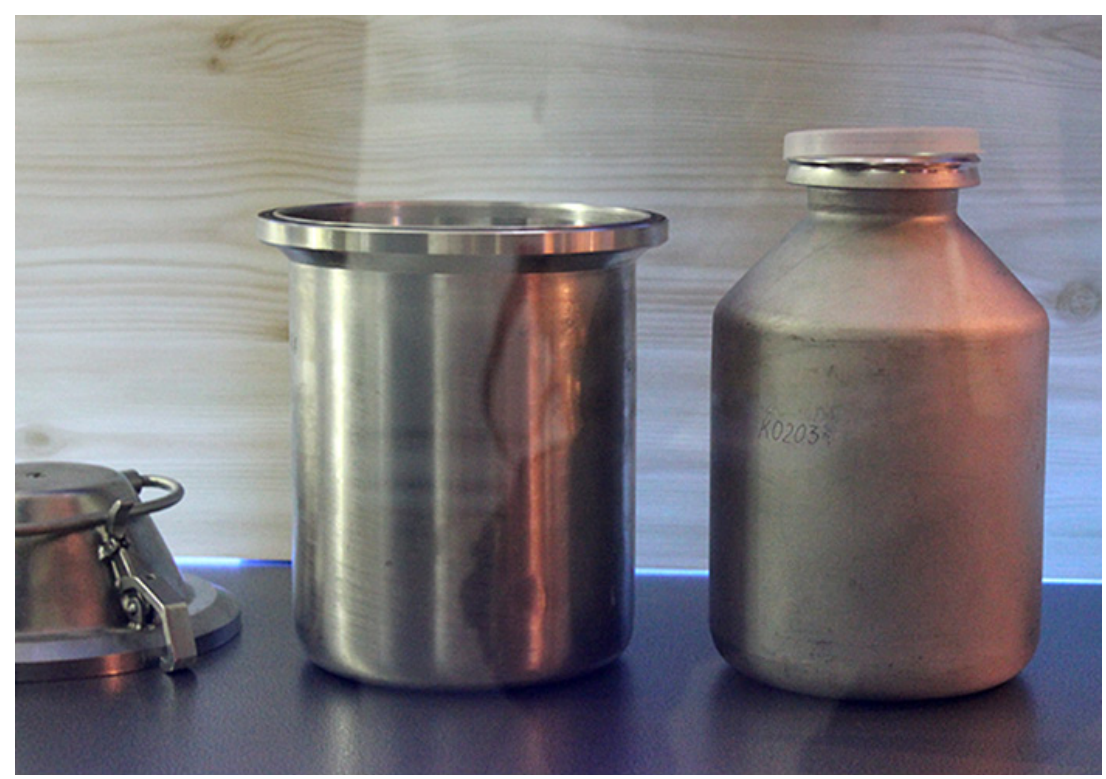

Figure 3 Ampoule of the RTSCH 108.010 and a bank for storing weapons-grade plutonium (previously such vessels were made of gold and platinum, stainless steel is currently used for their manufacture). Due to their high radioactivity, vast stocks of such products have accumulated at the Federal Unitary Enterprise "Mayak".

The levels of residual contamination of the platinum segments after completion of deactivation operations should not exceed 50 $\left(\mathrm{cm}^{2} \cdot \mathrm{min}^{-1}\right.$ in the smear. Deactivation was performed by three cycles of immersion for an hour each. Washing was performed for previously deactivated segments of platinum ampoules. Initially, the parts were treated with a nitrogen-oxalate solution that contained fluoride ions; the solution had the following composition: $380 \mathrm{~g} / \mathrm{l} \mathrm{HNO}_{3}, 2 \mathrm{~g} / \mathrm{l}$
$\mathrm{NaF}$ and $2 \mathrm{~g} / \mathrm{l} \mathrm{H}_{2} \mathrm{C}_{2} \mathrm{O}_{4}$. This solution provides not only a reduction in the initial contamination of the segment (smear 34,000 -. 40,000 $\left(\mathrm{cm}^{2} \cdot \mathrm{min}^{-1}\right.$ but also removal of the nickel-copper plating from the surface of platinum ampoules. The final deactivation of segments was conducted in the MDS solutions at $60^{\circ} \mathrm{C}$. The results are presented in Table 9, which shows levels of the initial contamination of platinum on a smear, i.e., the actual pollution of samples.

Table 9 Deactivation of platinum segments with MDS solutions

\begin{tabular}{|c|c|c|c|c|c|c|}
\hline \multirow[t]{2}{*}{ TWM } & \multirow{2}{*}{$\begin{array}{l}\text { Sample } \\
\text { number }\end{array}$} & \multirow[t]{2}{*}{ Side } & \multirow{2}{*}{$\begin{array}{l}\text { Initial surface } \\
\text { contamination } \\
\left(\mathrm{cm}^{2} \bullet \mathrm{min}\right)^{-1}(\text { on smear })\end{array}$} & \multicolumn{2}{|c|}{$\begin{array}{l}\text { Residual surface } \\
\text { contamination } \\
\left(\mathrm{cm}^{2} \cdot \mathrm{min}\right)^{-1} \text { (on a lie) }\end{array}$} & \multirow{2}{*}{$\begin{array}{l}\text { The total } \\
\text { coefficient of } \\
\text { deactivation } \\
\text { after three } \\
\text { cycles }\end{array}$} \\
\hline & & & & on smear & inflow & \\
\hline \multirow[t]{4}{*}{ MDS-I } & 12-Jan & inner & 200 & 23,0 & 23,1 & 9 \\
\hline & & outer & 1764 & 11,5 & 56,7 & 153 \\
\hline & 13-Jan & inner & 163 & Background & 11,2 & $>800$ \\
\hline & & outer & 630 & 2,5 & 34,5 & 252 \\
\hline \multirow[t]{4}{*}{ MDS-2 } & I7-Jan & inner & 40 & Background & 9,8 & $>200$ \\
\hline & & outer & 395 & Background & 14,0 & $>1900$ \\
\hline & 02-Feb & inner & 25 & Background & 17,4 & $>125$ \\
\hline & & outer & 329 & Background & $1 \mathrm{I}, 2$ & $>1600$ \\
\hline \multirow[t]{4}{*}{ MDS-3 } & 03-Feb & inner & 75 & Background & 13,3 & $>370$ \\
\hline & & outer & 686 & Background & 3,6 & $>3400$ \\
\hline & 07-Feb & inner & 50 & Background & 9,8 & $>250$ \\
\hline & & outer & 350 & Background & 23,8 & $>1750$ \\
\hline
\end{tabular}




\begin{tabular}{|c|c|c|c|c|c|c|}
\hline \multirow[t]{2}{*}{ TWM } & \multirow[t]{2}{*}{$\begin{array}{l}\text { Sample } \\
\text { number }\end{array}$} & \multirow[t]{2}{*}{ Side } & \multirow{2}{*}{$\begin{array}{l}\text { Initial surface } \\
\text { contamination } \\
\left(\mathrm{cm}^{2} \bullet \min \right)^{-1} \text { (on smear) }\end{array}$} & \multicolumn{2}{|c|}{$\begin{array}{l}\text { Residual surface } \\
\text { contamination } \\
\left(\mathrm{cm}^{2} \bullet \min \right)^{-1} \text { (on a lie) }\end{array}$} & \multirow{2}{*}{$\begin{array}{l}\text { The total } \\
\text { coefficient of } \\
\text { deactivation } \\
\text { after three } \\
\text { cycles }\end{array}$} \\
\hline & & & & on smear & inflow & \\
\hline \multirow[t]{4}{*}{ «MDS-4» } & I2-Feb & inner & 150 & Background & 37,8 & $>750$ \\
\hline & & outer & 1596 & Background & $1 \mid 4,8$ & $>7900$ \\
\hline & 13-Feb & inner & 175 & Background & 18,9 & $>870$ \\
\hline & & outer & 420 & Background & 13,3 & $>2100$ \\
\hline $380 \mathrm{~g} / \mathrm{l} \mathrm{HNO}_{3}+2 \mathrm{~g} / \mathrm{l} \mathrm{NaF}+$ & I5-Feb & inner & 50 & Background & $\mathrm{I}, 3$ & $>250$ \\
\hline \multirow[t]{3}{*}{$2 \mathrm{~g} / \mathrm{I} \mathrm{H}_{2} \mathrm{C}_{2} \mathrm{O}_{4}$} & & outer & 476 & Background & 2,8 & $>2380$ \\
\hline & I7-Feb & inner & 35 & Background & 0,7 & $>175$ \\
\hline & & outer & 440 & Background & 2,8 & $>2200$ \\
\hline
\end{tabular}

Currently, the deactivation of platinum ampoules is performed by remelting. To prepare ampules for remelting, they are subjected to three cycles of deactivation with oxalate in a nitric solution containing fluoride ions (to remove the copper-nickel coating and reduce the level of surface contamination), and one cycle of treatment with a $10 \%$ hydrochloric acid (to remove capillaries). To compare the quality of platinum deactivation by MDS agents with the current technology, Table 9 shows the data obtained at the final stage of deactivation using a nitrogen-oxalate solution. Deactivation effectiveness was judged by the value of residual contamination on the treated segments of platinum ampoules. Measurements of initial and residual contamination were carried out inflow and by a "dry smear" method using a radiometric dosimeter DKS. The main criterion for the evaluation of deactivation efficiency was a deactivation factor defined as a ratio of levels of radioactive contamination of samples before and after deactivation.

As can be seen from Table 9, that the deactivation coefficients obtained in treatment with conventional agents and with the tested compounds are practical of the same order for all samples, and that required levels of residual contamination of the platinum segments intended for remelting are achieved. However, it should be noted that in the case of the nitrogen-oxalate solution containing fluoride ion, residual contamination on the parts was minimal. Within a month after the deactivation of the platinum ampoule segments, they were subjected to radiometric control for determining their residual contamination. The obtained cartograms of measurements showed that the level of residual contamination did not change. Thus, considering the data as mentioned above, it can be concluded that MDS-type deactivation compounds are suitable for use at a stage of final deactivation of platinum ampoule segments intended for remelting.

\section{Assessing the possibility of using MDS-type agents for deactivating fabric materials, including linen and workwear}

Cotton fabric, for example, practically irreversibly absorbs radioactive colloids of hydroxides $\mathrm{Zr}, \mathrm{Nb}, \mathrm{Pu}$, and Po., ${ }^{1,3}$ Therefore, the test of the developed compounds on the tissues was of great importance. Cleaning solutions were prepared by dissolving the agent samples in water at $50 \pm 2{ }^{\circ} \mathrm{C}$. The concentration of each sample in each detergent solution was $1 \%$. Deactivation of fabric specimens was performed according to a standard procedure. The deactivation of fabric specimens with the detergent solution included the following five operations:

I. Treatment with a deactivation solution at $40-50^{\circ} \mathrm{C}$ for $10 \mathrm{~min}$;

II. Rinsing for 5 minutes at $20^{\circ} \mathrm{C}$;

III. Therapy with a deactivation solution at $40-50^{\circ} \mathrm{C}$ for $10 \mathrm{~min}$;

IV. Rinsing twice at $20^{\circ} \mathrm{C}$ for $5 \mathrm{~min}$;

V. Drying to complete dryness.

The workwear was made from cotton-type suit fabric - bleached moleskin.

The following solutions were used for contamination of the fabric specimens:

I. The solution of cesium ${ }^{137} \mathrm{Cs}$ chloride containing $10^{-3} \mathrm{~mol} / \mathrm{l}$ of potassium chloride solution with a volume activity of $2.0 \cdot 10^{7}$ $B q / l$, solution $\mathrm{pH}$ was in the range of 5.5 to 6.0 .

II. The solution of cerium ${ }^{144} \mathrm{Ce}$ chloride and praseodymium ${ }^{144} \mathrm{Pr}$ containing $10^{-3} \mathrm{~mol} / 1$ of potassium chloride solution with a volume activity of $2.0 \cdot 10^{7} \mathrm{~Bq} / \mathrm{l}$, solution $\mathrm{pH}$ was in the range of 5.5 to 6.0 .

III. Solutions of radioactive substances were applied to the center of fabric samples in an amount of $0.15 \mathrm{ml}$. Samples were dried at $22 \pm 2{ }^{\circ} \mathrm{C}$ for 18 to 20 hours. The contamination-deactivation cycle was repeated 4 times.

Levels of the initial and residual contamination were measured with the use of a radiometric dosimeter. The results of measurements were used for calculation of a deactivation coefficient equal to a ratio of the level of the initial contamination to the level of the residual contamination. The obtained data are shown in Table 10. As can be seen from the table, the proposed deactivation agent has a very high deactivation capacity regarding contamination with a mixture of radionuclides ${ }^{137} \mathrm{Cs},{ }^{144} \mathrm{Cе} \mathrm{и} \mathrm{и}{ }^{144} \mathrm{Pr}$ (cleaning is performed down to the background). 
Table 10 Results of deactivation with MDS-type agents in washing clothes

\begin{tabular}{lll}
\hline TMC & \multicolumn{2}{l}{ Coefficient of deactivation } \\
\hline & ${ }^{137} \mathrm{Cs},{ }^{144} \mathrm{Ce}$, and ${ }^{144} \mathrm{Pr}$ & ${ }^{144} \mathrm{Ce}$ and ${ }^{144} \mathrm{Pr}$ \\
MDS-I & $>300$ & 45 \\
MDS-2 & 160 & 21 \\
MDS-3 & 70 & 10 \\
MDS-4 & $>300$ & 40 \\
\hline
\end{tabular}

\section{Conclusion}

The paper presents data on creating a new detergent and decontamination agent with the code name MDS. We assessed the possibility of using a new generation of detergents with the conditional name MDS for the deactivation of various surfaces, equipment and workwear. A review of the deactivation methods currently used is reviewed. It was shown that the most typical pollutants are mixtures of ${ }^{137} \mathrm{Cs},{ }^{144} \mathrm{Ce},{ }^{144} \mathrm{Pr},{ }^{90} \mathrm{Sr}$ and ${ }^{239} \mathrm{Pu}$ radionuclides. As the analysis of the literature showed, all these elements are prone to the formation of chelate complexes. Therefore, substances that form stable, watersoluble complex compounds with the ions of these radionuclides should be essential components of deactivation solutions. When creating the recipe, the complexing agents were selected so that they had the most durable complexes with the alleged pollutants. For research and testing in real conditions, three types of special detergents of various compositions with the conditional name MDS were prepared. The form of these preparations includes components such as optimized surfactant mixtures, mixtures of complexing substances, corrosion inhibitors and processing aids. The studies conducted allowed us to assess the possibility of using these funds for the deactivation of premises, equipment and washing work clothes at the Federal Unitary Enterprise "Mayak" and its branch NIKIET in town Zarechny at Beloyarskyaya Nuclear Power Station in Russia. The deactivation efficiency was determined by the value of the residual contamination of the surface of the samples. The deactivating ability of MDS preparations concerning stainless, carbon steel and plastic contaminated with $\beta$ - and $\alpha$-emitting radionuclides was tested. The possibility of using MDS detergents for the deactivation of platinum ampoules stored as radioactive waste was studied. Studies have been carried out on the possibility of using detergent MDS for deactivation of fabric materials, including underwear and overalls. The tests showed the high efficiency of the developed detergent MDS, compared with existing and currently used tools.

\section{Acknowledgments}

None.

\section{Conflicts of interest}

The author declares there is no conflict of interest.

\section{References}

1. Ampelogova NI, Simanovsky Yu M, Trapeznikov AA. Deactivation in nuclear energy. In: M Energoizdat. 1982. p. 256.

2. Zimon AD, Pikalov VK. Deactivation. -M.: IzdAT, 1994. p. 338.

3. Gorodinsky SM, Goldstein DS. Deactivation of polymer materials. $2^{\text {nd }}$ ed. M.: Atomizdat, 1981. p. 187.

4. Konkin ED, Kizhnerova AV, Kuleshova EB. RF patent No. 2017244 , Method for the deactivation of stainless-steel surfaces. 1991.

5. Sorokin NM, Parfenov BG. RF patent No. 2033148, Paste for dry cleaning hands from contaminants. 1992.

6. Matkovskaya TA, Gnezdilov AA, Marchenko VI, et al. RF patent No. 2035074, Means for removing contaminants from radioactive and toxic metals. 1993.

7. Lebedev VI, Epikhin AI, Mareev GD, et al. RF patent No. 2066495, Method for deactivation of the surface of equipment and facilities of nuclear power plants. 1994.

8. Rudomino MV, Krutikova NI, Klochkov VN, et al. $R F$ patent No. 2110859, Detergent for removing contaminants from radioactive and toxic metals. 1996.

9. Kuznetsova NA, Sakhnenko OA, Kozina Yu. V. Development of a technological scheme for the deactivation of platinum wastes to return precious metals to the Russian state fund. Scientific and technical conference "TEAM-2015": a collection of abstracts. St. Petersburg: Publishing House of the Polytechnic University, 2015. p. 81-82.

10. Control levels of permissible volumetric activity of air, radioactive contamination of surfaces, individual radiation doses, and dose rates of ionizing radiation: KURB-2010: Instead of KURB-2004; Introduced 2010-01-01. Ozersk, Federal State Unitary Enterprise PO Mayak. 1997.

11. Kuznetsova NA, Zimin P Yu. Development of a technological scheme for the utilization of platinum ampoules of RTSCH 108.010. Report of Federal State Unitary Enterprise PO Mayak; - Ozersk, 2012. p. 26. 